\title{
Forgiveness: as attaining mental health among depressed patients
}

\begin{abstract}
Forgiveness plays a vital role from the recovery of mental and physical health issues. The main purpose of the study was to determine the importance of male and females' forgiveness in mental health and further find out the correlation between forgiveness and mental health among depressed patients. 120 diagnosed depressed patients randomly approached from Nishtar hospital Multan. Level of Forgiveness was measured through Heartland Forgiveness Scale ${ }^{1}$ and mental health of depressed patients was evaluated by Mental Health Inventory. ${ }^{2}$ Statistical Package of Social Sciences (SPSS) 22 version utilized to get the results. Correlation analysis indicated that forgiveness was positively and strongly correlated with mental health. The presence of forgiveness in depressed patient's life was found to attain mental health. Results revealed that female scored higher on forgiveness and mental health as compare to their male counterparts. Future implications for helping depressed patient's perceive presence of forgiveness in their lives are Forgiveness practice on daily basis is very helpful to increase the mental health and by embracing forgiveness, individuals can also embrace peace, hope, gratitude, happiness and joy these are path that lead to mental health.
\end{abstract}

Keywords: forgiveness, mental health, health, depressed patients
Volume 7 Issue 4 - 2017

\section{Momina Abid}

Psychologist, Special Education Department, Pakistan

Correspondence: Momina Abid, Psychologist, Special Education Department, Government of the Punjab, Pakistan, Email momianaabidII@gmail.com

Received: January 06, 2017 | Published: March 16, 2017

\section{Introduction}

The specific aspect of forgiveness, based on the often can be used for the classification of these definitions. For example some definitions refer to provisions for forgiveness, ${ }^{1,3,4}$ while others focus on single or special relationship relentlessly motives. ${ }^{5}$ Other forms of definition of forgiveness have an approach taxonomic check and a variety of destinations and forms of forgiveness. ${ }^{6}$ The Foundation for Inner Peace, Jampolsky \& Friedman, ${ }^{7-11}$ defining the forgiveness with seven criteria:

a. to a deferral of the exercise and vision,

b. A postponement to beliefs and attitudes,

c. a deferral of the affect,

d. a shift in the self-determination and personal responsibility,

e. (e), a postponement of the election, decision and the intention,

f. a transfer of a duality awareness of the unity of the conscience, and

g. a deferral in the identification of the gist qualitiesof the individual.

From the perspective of Foundation for Inner Peace, Jampolsky \& Friedman, ${ }^{7-11}$ forgiveness happens when a person is always emotionally supports processes, complaints, thoughts and beliefs attack on himself and others to collect good, value, the glory, the innocence, of love and of peace in both you and to a different person at the same time also from this point of view is the process of forgiveness is active when a person before an election consciousness/decision awarded and then the process of forgiveness to a higher power/Auto (e.g. the Holy Spirit). During this process, the projections are the property and are freed and peace and love as the goals set. Emotional forgiveness is based on a minimum scope of negative emotions, including but not limited to: resentment, bitterness and enmity and hatred, etc. Consorting to Worthington and his colleagues ${ }^{12,13}$ forgiveness works by the shift of unforgiveness or 'pollution' unforgiveness with apologies or positive, pro-social, positive emotions. At other side, Decisional forgiveness is based on beliefs about the future of relations with a transgressor. Worthington \& Scherer ${ }^{14}$ indicate that emotionally and decisional forgiveness can go hand in hand or in forms diverge interesting. While for example that forgiveness decisional often is able to advance to forgiveness emotionally and facilitate actually, it must always be the case. As Worthington and his colleagues defined the importance of emotions in the forgiveness, it is agreed that emotions plays a significant role in forgiveness. Emotional forgiveness refers to replace the negative emotions such as fear, pain, hurt resentment and anger with more positive emotions such as peace, love, happiness and joy. These emotions can be self and other focused. As decisional forgiveness defined by Worthington \& Scherer ${ }^{14}$ cognitively arbitrated conduct declaration on interactions inter personnel could we also keep the forgiveness decisional beliefs about a decisional forgiveness itself. This means that behavioral intentions might be involved in decisional forgiveness to future interactions with the collection of a transgressor as Worthington \& Scherer ${ }^{14}$ remark, but also about the merit of faith and the quality of the victim. In other words, beliefs about themselves as victims can be perceived. Just as important as what beliefs, interactions with the collection of a transgressor should develop in the future.

\section{Gender differences and forgiveness}

The gender-specific differences in the forgiveness can expect for several reasons. Firstly, the gender-specific differences may be a work unit for moderator's methodology. For example the path of forgiveness is not studying that may be causing the difference between the sexes. Secondly dispositional qualities can be associated with the replies you beautiful. ${ }^{5}$ Thirdly, there may be differences of the sexes in the trains touch affective responses to situations..$^{15}$ Fourth one is style bond that influence the tendency to forgive. ${ }^{16}$ Fifthly, the men can be tightened; Kohlberg's ${ }^{17}$ based on justice and the morale of the answers to the transgressions under core the battles, the vengeance or justice. 
Women can be attracted more than heat-based of the virtues that are more Gilligan's ${ }^{18}$ ethics of care. Sixthly, forgiveness can be influenced by the differences of the individual in coping. Seventh, the genderspecific differences in the forgiveness can also be influenced by differences in situation. Eight, religion can contribute to the tendency to forgive. In general, women are on average more religious than men. ${ }^{19}$ Religions tend to assess forgiveness. ${ }^{20}$

Health is a comprehensive concept and the definition of health change under the influence of the conscience and the setting of the society with different cultural and geographical situations. ${ }^{21}$ Mental health is as one of the dimension of health is a state of well-being in which the person can understand skills of their and others, the useful work, to bear the pressures of life and contribute to society. ${ }^{22}$ That is why mental health refers more than the absence of disease", but also "a state of complete well-being physically, mentally and socially". ${ }^{22}$ Mental health is slightly larger than the absence of Paniken, ${ }^{23}$ and in his general term refers to the health of the thought and the mental balance and characteristics of positive mental. ${ }^{24}$ In this sense the positive mental health is the foundation for the well-being and the effective functioning of the individual and for a community. Physical health and mental health cannot be exists without another.

Physical, mental and social activities are dependent to each other's. Beyond the health and the disease can coexist. Mutually exclude one another only if the defined health restrictive than the absence of illness. ${ }^{25}$ Recognition of Health as a state of balance, including the itself, others and the environment contributes, helps the communities and individuals to understand how their processing. The central concept of the mental health is in compliance with its vast and the importance of multiple between cultures. The physical health and mental health are closely connected with different mechanisms such as studies of the connections between depression and Cardiac disorders to prove. The importance of the mental health in the conservation of a good physical health and the restoration of the physics of the disease is now well shows, as it is to the contrary. Mental health is an important factor in the case of a change in the status of a community. Kleinman ${ }^{26}$ delineates the bunching of psychological and social health issues in "Broken communities" of shanty towns adjacent and slums and under vulnerable and marginal, civil violence, domestic violence, suicide, depression and disturbance.

Ghobari et al., ${ }^{27}$ investigated that forgiveness positively correlated to mental health and findings proved that the persons mostly forgive others shows less level of psychological issues like anxiety depression and psychological distress. Toussaint \& $\mathrm{Webb}^{6}$ stipulates that individual with high level of forgiveness have less level of psychological problems. A growing body of investigation showed that that forgiveness is positively associated with improved mental health. The study of the relationship of forgiveness with mental health also shows that a good strong relation of forgiveness with mental health. ${ }^{28-30}$

Berry et al., ${ }^{3}$ noted that likely forgiveness enhance mental health increased by shaping the interpersonal functioning, good behaviors and social support. Forgiveness is a real decision and emotional experiences of the people can change through forgiveness, a connection to the physical and mental health. ${ }^{31}$ People who forgive quickly and modify their thoughts about the offender's personality and term of causality, this modification affect the capabilities and concept of champion and by this way affects the physical and mental health.

Research study by Brown \& Philips ${ }^{32}$ forgiveness tendency is anticipative toward the lower levels of depression. Later on by reviewing the 18 researches regarding the importance and beneficence of forgiveness on mental health, it is also beneficial for physical, social and spiritual health. A growing body research showed that forgiveness improves physical and mental health. ${ }^{33}$ In reviewing the literature on forgiveness, ${ }^{34}$ showed that women have been found to score significantly higher on forgiveness. Miller, et al., ${ }^{35}$ deported through meta-analysis that females have high tendency to forgive as compare to males.

A constitutional division of health is mental health; hence no health without mental health (World Health Organization, 2010). Mental health issues are increased day by day in every individual and it affects 1 in 4 people. People suffer from many psychological disorders that affect their mental health. In depressed patients the ratio of poor mental health at its peak. It is observe that forgiveness is most neglected component in depressed patients which results many mental health problems. To overcome these mental health issues its time to give heed to factor like forgiveness that increase the positive mental health. Forgiveness is a requirement to cease the mental health problems like depression, sadness, resentment, revenge etc. Present research was aimed to examine the impact of forgiveness on mental health among depressed patients. Research also aimed to determine the gender difference in forgiveness and mental health.

\section{Hypothesis}

I. Forgiveness will positively correlate with mental health among depressed patients.

II. Forgiveness will significantly impact on mental health among depressed patients.

III. Forgiveness and Mental health will be high in female depressed patients than male depressed patients

\section{Methods}

\section{Participants}

The sample would be consisted of 120 depressed patients. Sample was collected through random sampling from Nishtar hospital Multan. Participant's age rage was 18 to 35years. Socioeconomic status of all participants was low. The patients who took in the research were willing to participate.

\section{Instruments}

In present research, 2 Instruments were used first, Heartland Forgiveness Scale ${ }^{1}$ and second scale was Mental Health Inventory. ${ }^{2}$

Heartland forgiveness scale: To assess dispositional forgiveness Heartland Forgiveness Scale $^{1}$ used in this study. The HFS is a self-report questionnaire with 18 items that assess dispositional forgiveness of one self (six-items), others (six-items), and situations (six-items) that contains 9 reverse items $(2,4,6,7,9,11,13,15,17)$. After summarizing the scores of the 7-point Likert scales, where 1 almost always false of me and 7 reflects almost always true of me, determined the perceived level of Forgiveness of the respondents. The possible range for total score of HFS is 18-126. The range of alpha coefficient is .84 to .87 for the total HFS scores and test-retest reliability is $.82 .{ }^{1}$ Reliability of Heartland Forgiveness Scale for this study is $(\mathrm{r}=.85)$.

Mental health inventory: To assess mental health of depressed patient used Mental Health Inventory. ${ }^{2}$ It is self-reported questionnaire and consists of 38 items. A global Mental Health Index score is used in 
present research. The specification of rating the items is frequency or intensity of symptoms that individual suffering from last one month.

\section{Procedure}

Initially permission got from the author of the scale before the data collection. Information was gathered through the utilization of a review survey, administered to depressed patients those were taken from. The survey comprised of two sections demographic variables and forgiveness and mental health constructs. Participants were informed about the purpose of study and assure about the confidentiality. Research participants were asked to fill questionnaire. Statistical Package of Social Sciences (SPSS) 22 version utilized to get the results.

\section{Results}

Statistical analysis was accomplished through Statistical Package of Social Sciences (SPSS) 22 version. Pearson's Product Moment Correlation was employed to see the relationship between forgiveness and mental health. Further regression analysis utilized to check the effect of forgiveness on mental health. Gender comparison was performed through independent t-test analysis.

Table 1 shows that forgiveness and mental health are positively correlated to each other $(r=.152, \mathrm{p}<0.05)$ depicting that as forgiveness will increase mental health will also increase in depressed patients.
Table I Pearson's Product Moment Correlation for Forgiveness with Mental Health

\begin{tabular}{lll}
\hline Variables & Forgiveness & Mental Health \\
\hline Forgiveness & - & \\
\hline Mental Health & $.152^{*}$ & - \\
\hline
\end{tabular}

Note: $\mathrm{N}=120 . *_{\mathrm{p}}<0.05$

Table 2 regression analyses revealed that forgiveness has significant positive impact on mental health among depressed patients.

Table 2 Simple liner Regression Analysis Showing Effect of Forgiveness on Mental Health

\begin{tabular}{llll}
\hline Predictor & B & Std. Error & B \\
\hline (Constant) & 103.877 & 12.09 & \\
Mental Health & 0.381 & 0.152 & 0.225 \\
\hline
\end{tabular}

Note: $R^{2}=0.050,{ }^{*} p 0.05$

Table 3 indicate that there is significant differences among male and female depressed patients $(t=1.652, d f=118, p<0.05)$. Result depicts that significant gender difference on the level of forgiveness among depressed patients. Result also reveals significant gender differences among depressed patients $(t=-2.230, d f=118, * p<0.05)$ on the level of mental health. The hypothesis accepted.

Table 3 Means, Standard Deviations, and t-values along Gender on Heartland Forgiveness Scale and Mental Health Inventory ( N = I20)

\begin{tabular}{|c|c|c|c|c|c|}
\hline & Male $(n=60)$ & Female $(n=60)$ & & & \\
\hline Variables & $M(S D)$ & $M(S D)$ & $\mathrm{t}(\mathrm{I} \mid 8)$ & $\mathrm{P}$ & Cohen's d \\
\hline Forgiveness & $76.80(9.517)$ & $79.87(10.909)$ & 1.652 & $.03^{*}$ & 0.304 \\
\hline Mental Health & |31.|3(17.996) & $138.49(16.602)$ & -2.23 & $.028 *$ & $-0.4 I$ \\
\hline
\end{tabular}

$\mathrm{N}=120 *_{\mathrm{p}}<0.05$

\section{Discussion}

The major objective of the research was to examine the correlational between forgiveness and mental health among depressed patients. First hypothesis about the significant positive correlation between forgiveness and mental health was supported. As the level of forgiveness increases in depressed patients their level of mental health will also increase. The findings of present research are in line with other research results. ${ }^{3,6,27,29,32,36-38}$ Second hypothesis of the research was about the impact of forgiveness on mental health as regression analysis showed that forgiveness has significant positive impact on mental health. Previous literature has suggested the benefits of forgiveness for the individual mental health, Toussaint \& Webb ${ }^{6}$ specified that people who forgive mistakes have expressing less level of psychological distress and shown high level of mental health. Finding of the study in line with literature by ${ }^{28,30}$ showed that positive association between forgiveness and mental health. Saif \& Bahari ${ }^{29}$ reported that positive correlation between forgiveness and the mental health.

Significant gender differences were found on forgiveness and mental health among depressed patients. Forgiveness and mental health will be higher in female depressed patients than male depressed patients. Previous researches supports this hypothesis ${ }^{34}$ showed that women have been found to score significantly higher on forgiveness. Miller et al. ${ }^{35}$ done meta-analysis and concluded that females are more forgiving than males.

One of the most robust findings in psychology related to mental health is gender differences. After reviewing the literature on mental health, literature revealed that problems linked to mental health mostly contributed by depression. ${ }^{39}$ Simonds \& Whiffen ${ }^{40}$ found that women diagnosed with mental health issues more than men. Higher risk of mental disorders is associated with females. ${ }^{41}$ Previous studies are not in consistent with the results of present research that mental health is high in female than male depressed patients. As previous research shows that men were more vengeful than women. ${ }^{42} \mathrm{~A}$ woman in cline to forgive more than men and forgiveness is linked to mental health. ${ }^{28}$

\section{Conclusion}

The findings of present study concluded that forgiveness has significant positive relationship with mental health. If the level of forgiveness will increase in depressed patients, mental health will also increase. Findings also represent that forgiveness has positive significant impact on mental health. Result of research showed that gender has significant differences on the level of forgiveness and metal health. It depicted that forgiveness and mental health is high in female than male among depressed patients. This research explored the importance of forgiveness for mental health. With hope, it is stated that this study would be helpful to elevate the awareness of mental health professionals regarding the forgiveness to achieve the high level of mental health.

\section{Implementation}

Forgiveness is a skill and skill can be learned. As research explore that to achieve the high level of mental health forgiveness play a vital role. 
a. This research suggests that many interventions can be used to improve the forgiveness such as; Universal Forgiveness Exercises, Serenity prayers, Positive Activities and Unconditional Other Acceptance.

b. Forgiveness trainings, workshops and seminars must be part of general education.

c. Forgiveness practice on daily basis is very helpful to increase the mental health as well as physical heath.

d. By embracing forgiveness, you can also embrace peace, hope, gratitude, happiness and joy these are path that lead to mental health.

\section{Acknowledgments}

None.

\section{Conflicts of interest}

Author declares there are no conflicts of interest.

\section{Funding}

None.

\section{References}

1. Thompson L, Synder C, Hoffman L. Heartland forgiveness scale. Faculty publications, Department of Psychology. 2005. p.452.

2. Viet CT, Ware JE. The structure of psychological distress and well-being in general populations. Journal of Consulting and Clinical Psychology. 1983;51(5):730-742.

3. Berry JW, Worthington EL, O'Connor LE, et al. Forgivingness, vengeful rumination, and affective traits. Journal of Personality. 2005;73(1):183-225.

4. Brown RP. Measuring individual differences in the tendency to forgive: Construct validity and links with depression. Pers Soc Psychol Bull. 2003;29(6):759-771.

5. McCullough ME, Rachal KC, Sandage SJ, et al. Interpersonal forgiving in close relationships II: Theoretical elaboration and measurement Journal of Personality and Social Psychology. 1998;75(6):1586-1603.

6. Toussaint L, Webb JR. Theoretical and empirical connections between forgiveness, mental health, and well-being. In: Worthington (Ed.), Handbook of Forgiveness, Brunner-Routledge, New York, USA. 2005. p.207-226.

7. Foundation for Inner Peace: A course in miracles. Glen Ellen, California, USA. 1975.

8. Jampolsky G. Love is letting go of fear. Berkeley, Celestial Arts, CA, USA. 1979

9. Jampolsky G. Forgiveness: The greatest healer of all. Hillsboro, Beyond Words Publishing, Inc, Oregon, USA. 1999.

10. Friedman PH. Friedman affect scale. Plymouth Meeting PA: Foundation for Well-Being, PA, USA. 1998.

11. Friedman PH. Integrative healing manual. Plymouth Meeting, PA: Foundation for Well-Being, PA, USA. 2000.

12. Worthington EL, Wade NG. The psychology of unforgiveness and forgiveness and implications for clinical practice. Journal of Social \& Clinical Psychology. 1999;18(4):385-418.

13. Worthington EL, Berry JW, Parrott LIII, et al. Unforgiveness, forgiveness, religion, and health. In: Plante \& Sherman (Eds.), Faith and health: Psychological perspectives. Guilford Press, New York, USA. 2001.
14. Worthington EL, Scherer M. Forgiveness is an emotion-focused coping strategy that can reduce health risks and promote health resilience: Theory, review, and hypotheses. Psychology \& Health 2004;19(3):385-405.

15. Bettencourt BA, Miller N. Gender differences in aggression as a function of provocation: A meta-analysis. Psychol Bull. 1996;119(3):422-447.

16. Bartholomew K, Horowitz LM. Attachment styles among young adults: A test of a four-category model. J Pers Soc Psychol. 1991;61(2):226-244.

17. Kohlberg L. Essays on moral development: Vol. 2 The psychology of moral development. Harper, New York, USA. 1984.

18. Gilligan C. in a different voice: Women's conceptions of self and of morality. Garland Publishing, New York, USA. 1994.

19. Freese J. Risk preferences and gender differences in religiousness: Evidence from the world values survey. Review of Religious Research. 2004;46(1):88-91.

20. Rye MS. The religious path toward forgiveness. Mental Health, Religion and Culture. 2005;8(3):205-215.

21. Jane W, Jannie N. Health Promotion Foundation for Practice. (2nd edn.), Harcourt Published, USA. 2000.

22. World Health Organization. The World Health Report 2001. Mental health: new understanding, new hope. World Health Organization, Geneva, USA. 2001

23. Kashala E. Mental Health of African School Children, PhD dissertation, University of Bergen, Norway. 2005.

24. Anasori M. The relationship between psychological health and happiness among the female and male students of Islamic Azad University. Applied psychology. 2008;2(6):75-84.

25. Sartorius N. Preface In: Goldberg \& Tantam (Eds.), The public health impact of mental disorders. Hogrefe and Huber, Toronto, Canada. 1990.

26. Kleinman A. Social violence: research questions on local experiences and global responses. Arch Gen Psychiatry. 1999;56(11):978-979.

27. Gobari Bnab B, Keyvanzadeh M, Vahdat Torbati SH. The relationship between forgiveness and mental health in medical college students. Journal of Psychology and Education. 2008;382:167-180.

28. Coyle CT, Enright RD. Forgiveness Intervention in post-abortion men. $J$ Clin Consult Psychol. 1997;65(6):1042-1046.

29. Saif S, Bahari F. The relatedness of couples forgiveness and their mental health. Psychological Studies. 2004;11:9-18.

30. Benda BB, Belcher JR. Alcohol and other drug problems among homeless veterans: A life-course theory of forgiveness. Alcoholism Treatment Quarterly. 2006;24(1-2):147-170.

31. Worthington EL. An empathy-humility-commitment model of forgiveness applied within family dyads. Journal of Family Therapy. 1998;20(1):59-76.

32. Brown RB, Philips A. Letting bygones be bygones: Further evidence for the validity of the Tendency to Forgive Scale. Personality and Individual Differences. 2005;38(3):627-638.

33. Exline JJ, Baumeister RF.Expressing forgiveness and repentance: Benefits and barriers. In: McCullough et al. (Eds.), Forgiveness: Theory, Research and Practice. 2000

34. Walker DF, Gorsuch RL. Forgiveness within the Big Five personality model. Personality and Individual Differences. 2002;32(7):1127-1137.

35. Miller AJ, Worthington EL, McDaniel MA. Gender and forgiveness: A Meta-analytic review and research agenda. Journal of Social and Clinical Psychology. 2008;27(8):843-876. 
36. Maltby J, Macaskill A, Day J. Failure to forgive self and other: a replication and extension of the relationship between forgiveness, personality, social desirability and general health. Personality and Individual Differences. 2001;30(5):881-885.

37. Lawler KA, Younger JW, Pieferi RL, et al. The unique effect of forgiveness on health: an exploration of pathways. J Behav Med. 2005;28(2):157-167.

38. Lawler-Row KA, Piferi R1 . The forgiveness personality: Describing a life well lived? Personality and Individual Differences. 2006;41(6):1009-1020.

39. Piccinelli M, Homen FG. Gender differences in the epidemiology of affective disorders and schizophrenia. World Health Organization, Geneva, USA. 1997.
40. Simonds VM, Whiffen VE. Are gender differences in depression explained by gender differences in co-morbid anxiety? J Affect Disord. 2003;77(3):197-202.

41. Kessler RC, Mc Gonagle KA, Swartz M, et al. Sex and depression in the National Comorbidity Study I: lifetime prevalence, chronicity and recurrence. J Affect Disord. 1993;29(2-3):85-96.

42. McCullough ME, Bellah GC, Kilpatrick SD, et al. Vengefulness: Relationships with forgiveness, rumination, well-being, and the Big Five. Personality and Social Psychology Bulletin. 2001;27(5):601-610. 